\title{
Sympatric speciation
}

\author{
Krishna Kumar Verma \\ HIG 1/327, Housing Board Colony, Borsi, Durg, Chhattisgarh 491001, India \\ Email: kk.sheel@gmail.com
}

\section{Date of publication (online): 26 April 2010 Date of publication (print): 26 April 2010 ISSN 0974-7907 (online) | 0974-7893 (print)}

\section{Editor: Pierre Jolivet}

\section{Manuscript details:}

Ms \# 02367

Received 15 December 2009

Finally accepted 31 March 2010

Citation: Verma, K.K. (2010). Sympatric speciation. Journal of Threatened Taxa 2(4): 820-823.

Copyright: ( ) Krishna Kumar Verma 2010 Creative Commons Attribution 3.0 Unported License. JoTT allows unrestricted use of this article in any medium for non-profit purposes, reproduction and distribution by providing adequate credit to the authors and the source of publication.

Author Details: K.K. VERMA is a PhD in Zoology, and has taught Zoology/Entomology for about 35 years in M.P. Govt. P.G. colleges. What perhaps is specially notable is that out of 67 research/review papers, published by him in national and international journals 44 have been published after his retirement in 1991 .
Abstract: The prevailing notion is that allopatry is the main driver of divergence between populations, leading to speciation. But a number of recent studies show that speciation occurs in sympatry too, that sympatric speciation is quite common, perhaps more common than hitherto believed. Such studies have been reviewed in this communication.

Keywords: Allopatry, character displacement, divergence, host switching, incipient speciation, orchids, sexual conflict, sympatry.

\section{INTRODUCTION}

Notions about allopatric and sympatric speciation include a spatial dimension. In case related nascent species are in different geographical areas, allopatry is obvious. However, related species may occupy the same general area, but they may be adapted to different niches; in that situation too some spatial separation is involved. That is why Fitzpatrick et al. (2008) have asked "What, if anything, is sympatric speciation?". Among diverging species there is a stage of only partial reproductive isolation, therefore, there may be a hybridization zone between their preferred niches. To decide about allopatry and sympatry in field work in a limited area is generally extremely difficult. Realizing this difficulty Fitzpatric et al. (2008) have pointed out that to apply the concept of sympatry in its theoretical extreme (i.e. even incipient and related species, occupying separate subdivisions of the ancestral range are not to be taken as sympatric) is nearly impossible. In the following discussion diverging species, with small/partial spatial separation between them, have been taken as sympatric.

\section{Divergence among associated organisms}

In parasite-host, phytophagous insect-host plant and plant-pollinator associations there is co-evolution and consequent divergence in both the sides involved and as pointed out by Kruger et al. (2009), there is a sort of arms race between them, resulting in higher speciation and extinction rates in the associates. Kruger et al. (2009) have studied species richness in parasitic cuckoos. They point out that there is almost no difference between parental and parasitic cuckoos in the number of species per genus. However, a cladogenesis test by them has shown that brood parasitism is associated with significantly higher rates of extinction and speciation. Further they point out that subspecies diversification rate is twice as much in parasitic cuckoos as in parental ones. Another important observation by the authors is that parasitic cuckoos, with more recognized subspecies, have more hosts. Obvious inferences, from the studies of Kruger et al. (2009), are that parental cuckoos evolve defenses against new brood parasites, that there are co-evolutionary changes both in the parental and parasitic species and that the parasitic ones not only show stepped up speciation but also increased rate of extinctions, if the new host develops effective defenses against a new brood parasite. These changes take place in sympatry, if we take sympatry in a little broader 
meaning, as suggested above.

\section{Host switching among phytophagous insects}

Two species of the chrysomelid beetle genus Chrysochus in North America are C. auratus and C. cobaltinus. Chrysochus species live on plants of Apocynaceae and Asclapiadaceae. Some species of these plant families contain the toxic compounds cardenolides. $C$. auratus and $C$. cobaltinus have their food plants with cardenolides, while all other species of the genus Chrysochus live and feed on plants without these toxic compounds. Labeyrie \& Dobler (2004) have prepared and compared DNA profiles of the cardenolides and non-cardenolides feeding species of Chrysochus, and have noted only one small and consistent difference between the two. While the latter species have the code for asparagine at the position 122, the cardenolides feeding species have at this position the code for histidine. Thus it seems that a small mutational change at this point has helped the two species to invade a new niche, viz. the host plants with cardenolides, and that this change has occurred in sympatry. Agrawal et al. (2009) have pointed out that production of latex and cardenolides by plants is a defense device meant to reduce herbivory in the extant communities, but specialized herbivores employ several mechanisms to circumvent the negative effect of such defensive devices of plants. A newly coming up mutation in a herbivore population may result in a newly acquired trait, which may counteract the adverse effect of the defensive plant toxins, thus help the mutant form to shift to a new niche and move along a line of diversification and this may happen in sympatry. Borghuis et al. (2009) have phylogenetically analyzed species of the beetle genus Galerucella. On the basis of their results they have inferred host switching among the species, as they find several sister taxa using unrelated host plants in sympatry. Gomez-Zurita (2008) has discussed speciation in the chrysomelid beetle genus Timarcha On the basis of genetic and phylogenetic studies, he has concluded that, while most species of the genus have evolved in allopatry, in some cases sympatric speciation has occurred due to chromosomal changes, host plant switching, or both.

\section{Orchids and their pollinators}

Orchids (Orchidaceae) are a highly diversified and a species rich family. It is estimated that there are nearly 30,000 naturally occurring species of orchids (MondragonPalomino \& Pfennig 2009). These plants have a number of different devices to attract pollinating insects. About one third of the species have taken to deceiving the pollinators; the deceit may be visual, aromatic, tactile, or all three together (Pollan \& Ziegler 2009). Rewarding species offer nectar to the pollinator. Deceiving species deceive through presenting the appearance in their floral morphology of a nectar producing species or giving out the scent of a nectar offering species, but do not produce nectar. Some deceivers have taken to sexual deception through some petals of the flower presenting the appearance of the rear end of the abdomen of a female of the pollinator species and also through production of the scent of the pollinator female. A male of the pollinator is thus invited for a pseudocopulation with the flower. Species specific relation between an orchid species and its pollinator is traditionally considered as the main reproductive isolation mechanism among orchids (Cozzolino et al. 2005a) but, because of deception among orchids, a mixed pollen load is expected on the pollinator due to visiting deceptive, as well as, rewarding species of orchids. Cozzolino et al. (2005a) have found bees and flies, which are orchid pollinators in the Mediterranean region, carrying hemipollinaria belonging to nine different orchid species. In this situation hybridization between orchid species is expected. Cozzolino \& Widmer (2005b) have recommended observations on the behaviour of orchid pollinators, experimental crossings and the use of molecular markers for studying orchid hybridization. Hybrids of the Sardinian orchids Ophris tricolor and $O$. incubacia have been studied by Cortis et al. (2009). They find the hybrids with features which are intermediate between the parental species, in labellum morphology. The hybrids and the parentals have been noted as producing a similar mix of scents. But the hybrids have been observed to produce significantly less fruits and seeds than the parentals. Genetically the hybrids have been found to be of the first generation resulting from the hybridiztion. Thus it has been inferred that a post-mating barrier was keeping the two orchid species apart. But such barriers to successful speciation through hybridization should not be common among orchids, because, as Pollan \& Ziegler (2009) have pointed out, at present there are about $1,00,000$ registered hybrid orchids. As Venditti \& Pagel (2009) have said, speciation through hybridiztion is more common than previously thought. The species specific relationship between an orchid species and its pollinator is through the exact nature of the scent produced by the former. This situation may also help sympatric origin of a new orchid species. As said by Pollan \& Ziegler (2009), a mutation in an orchid may result in a slight alteration in its scent and the altered scent may attract the attention of a new pollinator, while the original pollinator may not respond at all. This will create a reproductive isolation between the mutant and the original orchid, thus speciation may be initiated in sympatry.

\section{Character displacement and sympatric divergence}

Pfennig \& Pfennig (2009) have discussed at length ecological and reproductive character displacement. They point out that, if two species or two incipient species 
live in the same habitat, selection operates between them to minimize competitive use of resources or to minimize reproductive interference by character displacement or displacement of traits associated with resource use and reproduction. Such displacement may take place both in allopatry and in sympatry. In sympatry it may occur between two closely related species or incipient species and in both such cases it leads to further divergence and phenotypic differences between them. The role of selection in character displacement has been discussed by the authors. An illustrative example of character displacement is in Verma \& Shrivastava (1985). They have studied niche separation between two species of the tortoise beetle Aspidomorpha (Aspidomorpha), A. miliaris and $A$. sanctae-crucis, which live and feed on leaves of the same host plant, Ipomoea fistulosa, and have similar geographic distribution in India (Maulik 1919). While $A$. sanctae-crucis adults feed on the marginal parts of a leaf, $A$. miliaris, as adults, feed on the deeper parts of a leaf lamina, making roundish/ovoid holes (Figs. 1 a \& b). Larvae of $A$. miliaris are gregarious, living in groups up to the time of pupation. When feeding, they form a tight row along a leaf margin and when at rest, they make an oval cycloalexic group (Verma 1992) on a leaf (Figs. $2 \mathrm{a} \& \mathrm{~b})$. In contrast the larvae of $A$. sanctae-crucis live isolated and scattered on leaves. They feed on deeper parts of the leaf lamina, making roundish holes, like the adults of $A$. miliaris. A. miliaris is found on the Ipomoea weed in more humid areas, whereas $A$. sanctae-crucis prefers weed growth in drier areas. Besides these behavoural and ecological differences, there are also morphological differences between the two species, e.g. in their mandibular structure and in the shape of the basal part of their elytra. It is also notable that, in spite of these differences, there is a some overlap between the niches of the two species. Pfennig \& Pfennig (2009) point out that character displacement furthers divergence between incipient or partly diverged species. Hence sympatric speciation mechanism may include character displacement.

\section{Incipient speciation}

Speciation is a continuum, during which there is a gradual acquisition of reproductive isolation and a species is an arbitrarily chosen stage in this continuum (Verma 2006). In the continuum the stage chosen, to be designated as a species, is generally at a pronounced level of reproductive isolation and divergence. Cases of incomplete speciation have been reviewed by Nocil et al. (2008). They point out that ecological divergence often leads to weak reproductive isolation and small genetic differentiation between related populations. In such cases divergence occurs in a limited spatial dimension. Arias et al. (2008) have studied, through mimetic colour pattern and molecular genetic data, incipient ecological
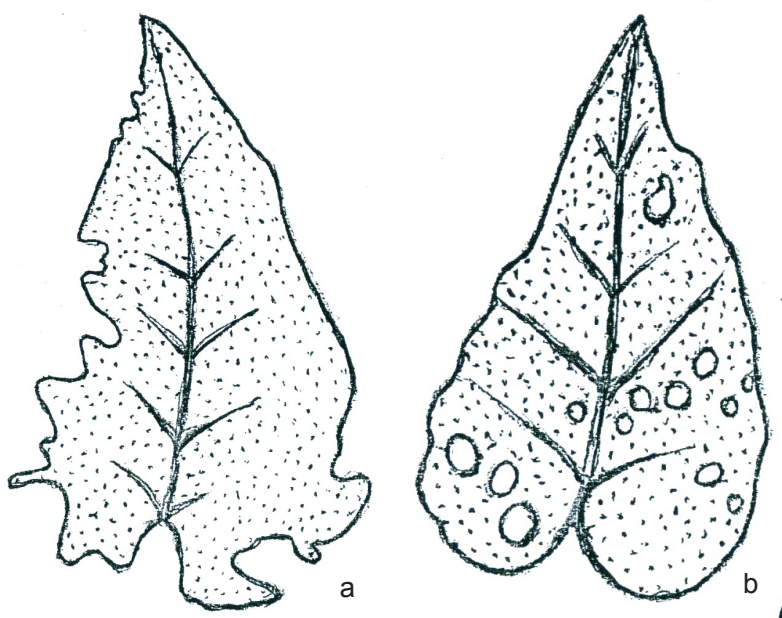

Figure 1. Ipomoea leaves with feeding damage by adults of the tortoise beetle Aspidomorpha.

a - Damage by $A$. sanctae-crucis; $b$ - Damage by $A$. miliaris.

(Based on photographs in Verma \& Shrivastava 1985)
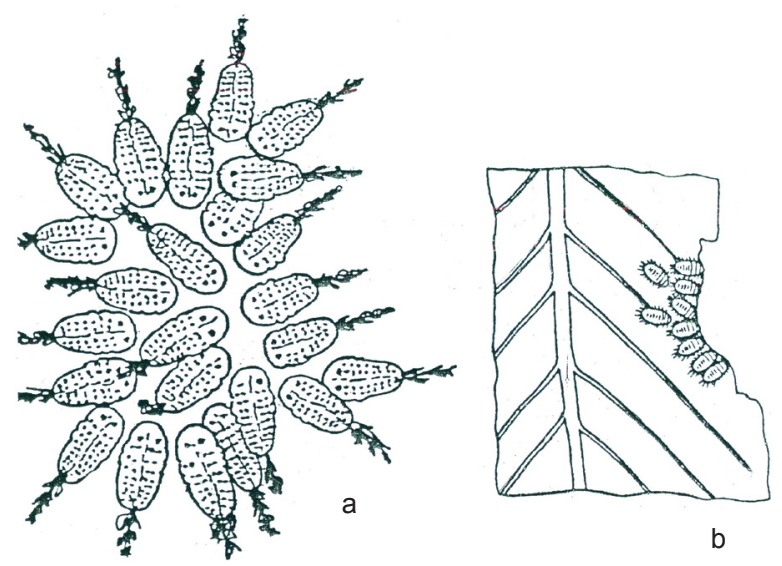

Figure 2. Last instar larvae of the tortoise beetle Aspidomorpha miliaris.

a - The larvae at rest in a cycloalexic arrangement. Exuviae carrying caudal ends of the larvae form the periphery of this ovoid grouping; $b$ The larvae in a feeding position in a tight row at a margin of an Ipomaoea leaf. (Fg. 2 (b) is based on a figure in Verma 1992.)

speciation in Heliconius butterflies. They have found a hybrid zone between two subspecies of Heliconius erato, namely $H$. erato venus and $H$. erato chestertonii, suggesting an incomplete reproductive isolation between the two. Further the authors have found that $H$. erato venus is monophyletic in origin, and well differentiated from $H$. erato chestertonii, suggesting no introgression between the two in the past. $H$. erato chestertonii occurs at higher altitudes than other races of $H$. erato. This subspecies has well maintained its integrity in spite of a high level of hybridization and is thus well on the way to further divergence and speciation. Such instances of incipient speciation have been often taking place with limited spatial separation; hence they may be taken as taking place in sympatry. Incipient speciation may lead to further divergence, not only through growing reproductive isolation, but also through hybrid speciation. Hybrid 
speciation generally does not happen in animals, due to some pre- or post-mating barriers. But in a small number of cases, due to crosses between parapetric populations of only partly diverged or incipient species or members of the same species complex, viable hybrids are produced, which start new lineages. This situation has been recorded by Gomez-Zurita (2008) in the chrysomelid beetle genus Timarcha. From his genetic and phylogenetic study on species of this genus he has inferred that within the $T$. goettingensis species complex hybrid speciation has occurred.

\section{Sexual conflict and divergence}

The female chichlid fishes in the African Lake Malawi, living against a rocky bottom, have a mutant body colour, orange-blotch (OB), which is advantageous to them, as it gives them crypsis against a mottled rocky substratum (Robert et al. 2009). But this body colour has a disadvantage; it has disrupted the species specific male colour pattern for mate choice. This sexual conflict has resulted in a selection in favour of brightly coloured males. Elsewhere the original body colour, brown barred (BB) continues as the favoured colour, as it makes the fishes inconspicuous to predators. The genetic divergence between chichlids, living against rocky lake bottom and those in other areas is developing. Roberts et al. (2009) believe that similar genetic conflicts have played an important role in diversification and speciation in chichlids in African lakes. Here it would be relevant to recall the views of Rodriguez (2009), according to whom a trait may evolve in a nonsexual context, but may lead to a sensory bias affecting mate choice. Thus it may help fuel rapid evolution through sexual selection.

\section{Conclusion}

It has been traditionally believed that speciation has been mostly in allopatry. But now it is being realized that sympatric speciation also plays an active role in producing species divergence and is more common in speciation than previously believed (Venditti \& Pagel 2009).

\section{REFERENCES}

Agrawal, A.A., M. Fishbein, R. Halitschke, A.P. Hastings, D.L. Rabosky \& S. Rasmann (2009). Evidence for adaptive radiation from phylogenetic study of plant defenses. Proceedings of the National Academy of Sciences (Early Edition). DOI: 10.1073/pnas.0904862 106

Arias, C.F., A.G. Munoz, C.D. Jiggins, J. Mavarez, E. Bermingham \& M. Linares (2008). A hybrid zone provides evidence for incipient ecological speciation in Heliconius butterflies. Molecular Ecology DOI: 10.1111/j.1365294X.2008.03934.x

Borghuis, A., J.V. Groenendael, O. Madsen \& J. Ouborg (2009). Phylogenetic anlyses of the leaf beetle genus
Galerucella: Evidence for host switching at speciation? Molecular Phylogenetics and Evolution 53: 361-367.

Cortis, P., N.J. Vereecken, F.P. Schiestl, M.R. Barone Lumaga, A. Scrugli \& S. Cozzolino (2009). Pollinator convergence and the nature of species' boundaries in sympatric Sardinian Ophrys (Orchidaceae). Annals of Botany 104: 497-506.

Cozzolino, S., F.P. Schiestl, A. Muller, O. De Castro, A.M. Nardella \& A. Widmer (2005a). Evidence for pollinator sharing in Mediterranean nectar-mimic orchids: absence of premating barriers? Proceedings of the Royal Society B 272: 1271-1278.

Cozzolino, S. \& A. Widmer (2005b). Orchid diversity: an evolutionary consequence of deception? Trends in Ecology and Evolution 20(9): 487-494.

Fitzpatric, B.M., J.A. Fordyce \& S. Gavrilets (2008). What, if anything, is sympatric speciation? Journal of Evolutionay Biology. DOI: 10.1111/j.1420-9101.2008.01611.x

Gomez-Zurita, J. (2008). Species and speciation in Timarcha, pp.17-39. In: Jolivet, P., J. Santiago-Blay \& M. Schmitt (eds.). Research on Chrysomelidae (vol. 1). Brill, Leiden, The Netherlands.

Kruger, O., M.D. Sorenson \& N.B. Davies (2009). Does coevolution promote richness in parasitic Cuckoos? Proceedings of the Royal Society B. DOI: 10.1098/ rspb.2009.1142

Labeyrie, E. \& S. Dobler (2004). Molecular adaptation of Chrysochus leaf beetles to toxic compounds in their food plants. Molecular Biology and Evolution 21(2): 218-221.

Maulik, S. (1919). Fauna of British India, volume on Coleoptera, Chrysomelidae, Cassidinae and Hispinae. Taylor and Francis Ltd., London.

Mondragon-Palomino, M. \& G. Theiben (2009). Why are orchid flowers so diverse? Reduction of evolutionary constraints by paralogues of class B floral homeotic genes. Annals of Botany 104: 583-594.

Nosil. P., L.J. Harmon \& O. Seehausen (2008). Ecological explanations for (incomplete) speciation. Trends in Ecology and Evolution DOI: 10.1016/j.tree.2008.10.011

Pfennig, K.S. \& D.W. Pfennig (2009). Character displacement: Ecological and Reproductive responses to a common evolutionary problem. The Quarterly Review of Biology 84(3): 253-276.

Pollan, M. \& C. Ziegler (2009). Love and lies. How do you spread your genes around when you're stuck in one place? By tricking animals, including us, into falling in love. National Geographic Magazine, September 2009. (http://ngm. nationalgeographic.com/2009/09/orchids-text) Downloaded on $29^{\text {th }}$ Aug. 2009.

Roberts, R.B., J.R. Ser \& T.D. Kocher (2009). Sexual conflict resolved by invasion of a novel sex determiner in Lake Malawi chichlid fishes. Science Express, $1^{\text {st }}$ October 2009 (www.sciencexpress.org) Downloaded on $2^{\text {nd }}$ October 2009.

Rodriguez, R.L. (2009). Trait duplication by means of sensory bias. Behavioral Ecology (Advance access publication on $4^{\text {th }}$ October 2009) DOI: 10.1093/beheco/arp130

Venditti, C. \& M. Pagel (2009). Speciation as an active force in promoting genetic evolution. Trends in Ecology and Evolution DOI: $10.1016 /$.t.tree.2009.06.010

Verma, K.K. (1992). Cycloalexy in the tortoise beetle Aspidomorpha miliaris (Coleoptera, Chrysomelidae). Chrysomela 26: 6.

Verma, K.K. (2006). Have modern species concepts failed? Bionotes 8(4): 88-91.

Verma, K.K. \& R.K. Shrivastava (1985). Separate niches for two species of Aspidomorpha living on Ipomoea fistulosa M. and de Bary (Coleoptera, Chrysomelidae). Entomography 3: 437-446. 